\title{
Políticas educacionais nos anos 90: a formação de professores no Brasil e em Portugal
}

\section{Educational policies in the 90s: the graduation of teachers in Brazil and Portugal}

\author{
José Augusto Pacheco* \\ Maria Célia Marcondes de Moraes ${ }^{* *}$ \\ Olinda Evangelista*
}

\begin{abstract}
RESUMO
O trabalho tem como objetivo principal analisar, em Portugal e no Brasil, no período dos anos 90, as políticas públicas e respectivas influências no campo da Educação e da Formação de Professores. Pretende-se, de igual modo, identificar as tendências e os conceitos constitutivos das políticas educacionais, sobretudo o particular uso que se faz da noção de "competências", a partir de documentos de organismos nacionais e agências multilaterais. Procurar-se-á, por um lado, identificar a forma pela qual as inflexões de natureza teórica são difundidas na documentação em tela e, por outro, entender de que modo determinados conceitos são pragmaticamente naturalizados, modificados, abandonados, substituídos ou re-significados. Tal inflexão teórica pode ser particularmente apreendida no âmbito das políticas educacionais relativas à formação docente, atendendo, sobretudo, ao modo como foi efetivada no Brasil e em Portugal.

Palavras-chave: políticas educacionais; formação de professores; competências.
\end{abstract}

\footnotetext{
*Professor do Instituto de Psicologia e Educação da Universidade do Minho-Portugal.

** Doutora em Ciências Humanas (Educação) pela PUC/RJ, Professora Titular da Universidade Federal de Santa Catarina,. E-mail: mcmm@uol.com.br.

${ }^{* * * *}$ Professora da Universidade Federal de Santa Catarina
} 


\section{ABSTRACT}

This work analyses, as its main goal, the public policies and its respective influences in the land of Education and teachers graduation in Portugal and in Brazil, during the period of the 90s. In the same way, this work intends to identify the tendencies and constitutive concepts of Educational policies, mainly the particular use of "competencies" notion, based on documents of national organisms and multilateral agencies. This research, by one side, intends to identify the way by that the theoretic nature inflections are broadcast in the analyzed documents and, in another side, it tries to understand in which way determined concepts are pragmatically naturalized, modified, abandoned, substituted and re-meant. This theoretical inflection can be particularly seized in the ambit of educative policy relative to teachers graduation mainly accommodating the way this was effectuated in Brazil and in Portugal.

Key-words: educational policy, teachers graduation, competencies.

\section{Introdução}

$\mathrm{O}$ artigo tem como objetivo principal analisar, em Portugal e no Brasil, no período dos anos 90, as políticas públicas e respectivas influências no campo da Educação e da Formação de Professores. Pretende-se, de igual modo, identificar as tendências e os conceitos constitutivos das políticas educacionais na década de noventa, sobretudo o particular uso que se faz da noção de "competências", a partir dos relatórios e demais documentos de organismos nacionais e agências multilaterais.

O elevado grau de competitividade no mundo de hoje faz da educação a alavanca para a sociedade do conhecimento e a da informação (LASH, 1999; TOURAINE, 1999) que se oferecem como alternativa à sociedade industrial marcada por relações de produção estáveis. As novas tecnologias, presentes na sociedade da informação, que resultam da fragmentação das cadeias de produção, levam à configuração e distribuição espacial dos processos produtivos, com particular incidência nas novas teias de relações político-institucionais e nas constantes inovações no processo de divulgação e globalização do conhecimento, transformado num investimento sujeito às regras de mercado. Como produto, bem ou serviço, a Educação converte-se num alicerce central não confinada ao espaço escolar, mas ampliada para os processos gerais da educação permanente e do desenvolvimento ao longo da vida, eleita como fator estratégico na construção desta nova sociedade. A escola tradicional, a educação formal, os antigos parâmetros educacionais, tornaram-se rapidamente obsoletos. Procura-se, agora, uma nova pedagogia, um projeto educativo de outra natureza.

A reestruturação produtiva em curso, dessa perspectiva, exige que se desenvolvam capacidades de comunicação, de raciocínio lógico-formal, de criatividade, de articulação de conhecimentos múltiplos e diferençados de modo a capacitar o aluno-cidadão a enfrentar sempre novos e desafiantes problemas. Mais ainda, diante da velocidade das mudanças, as requalificações tornam-se imperativas e a especialização flexível transforma-se no paradigma de formação exigido pelo mercado. O desenvolvimento dessas "competências" (transferable 
skills) exige níveis sempre superiores de escolaridade, visto que repousam no domínio teórico-metodológico que a mera experiência é incapaz de garantir (MORAES, 2000).

Esse processo repercute na definição das políticas públicas que constituem, hoje em dia, um dos campos multidisciplinares que mais têm desencadeado o interesse de intelectuais e políticos. Por serem controversas e envolverem inúmeros interesses conflitantes, situados na efemeridade temporal, a discussão realizada permanece mais ao nível da opinião do que ao da discussão conceptual lastreada em referentes epistemológicos consistentes. No entanto, não ignoramos que a toda política subjaz uma intencionalidade teórica. Desse modo, pretendemos trabalhar as políticas públicas no contexto do papel que as universidades desempenham na análise crítica das orientações teóricas que fundamentam as opções políticas em termos educacionais. Procurar-se-á, por um lado, identificar a forma pela qual as inflexões de natureza teórica são difundidas na documentação em tela e, por outro, entender de que modo determinados conceitos são pragmaticamente naturalizados, modificados, abandonados, substituídos ou re-significados. Tal inflexão teórica pode ser particularmente apreendida no âmbito das políticas educacionais relativas à formação docente, atendendo, sobretudo, ao modo como foi efetivada no Brasil e em Portugal.

A despeito do interesse em discutir as semelhanças e as diferenças existentes entre as reformas educacionais brasileira e portuguesa, não se pode perder de vista que, no caso de Portugal, tal reforma vem sendo empreendida a partir de meados dos anos 80 . No caso do Brasil, conquanto a reforma venha sendo realizada desde o início dos anos 90 , no que diz respeito à formação do docente ainda se encontra nos planos normativos e não se efetivou na prática. Cabe ressalvar, ainda, que nossos estudos não tiveram por base um referencial analítico que colocasse em iguais condições os dois países em vista das diferenças sociais e econômicas dadas, especialmente, pela posição que cada um ocupa na organização internacional do trabalho.

Não cabe, neste artigo, discutir as políticas educacionais sobre a formação docente no que concerne aos seus desdobramentos práticos, mas tão só acompanhar a ordem do discurso e das lógicas que confluem, necessariamente, na afirmação da importância estratégica do professor e, no que nos interessa mais de perto, na elaboração de políticas de formação, sobretudo no âmbito do ensino superior.

\section{Brasil: a elevação da formação docente ao nível superior}

No caso do Brasil, as recentes alterações legais estão permeadas pelas exigências dos organismos multilaterais, efetivando-se, ainda que com resistências, 
as indicações deles emanadas. A conceituação no campo da formação tem sido articulada com medidas do Banco Mundial, da Unesco e da Cepal que vêem no professor, protagonista da modernização, um sujeito a ser profissionalizado, exigindo-se-lhe um "saber fazer" que supere o descompasso entre sua prática de ensino e a vida. Para tanto foi necessário o peculiar estratagema de deslegitimação de seus saberes teóricos e práticos seguidos do esforço de convencê-los de que precisam de uma re-profissionalização, re-profissionalização que vem desconectada das raízes de seu métier (EVANGELISTA, MORAES e SHIROMA, 2000).

O ideário da reforma educacional em curso, paradoxalmente, identifica no professor não só o responsável pelas dificuldades do sistema público de ensino, como lhe atribui o condão de extirpá-las. A estratégia discursiva engendrada pelos órgãos oficiais construiu não só a imagem do professor como um não-profissional, cujas ações redundavam não raro em perdas para os alunos e para o sistema de ensino, mas também a representação de que só ele criaria as condições para a realização do projeto governamental.

Os determinantes das reformas lastreiam-se em razões que ultrapassam o campo das preocupações com a qualificação docente, ou seja, o Estado projeta no professor a produção das competências demandadas pelo mercado e em total sintonia com o leitmotiv das reformas. Algumas destas respostas estão nas diretrizes curriculares, pautadas na formação de valores, atitudes e comportamentos, articuladas quer à centralidade conferida ao professor na realização do plano governamental, quer àquelas competências que assegurariam a empregabilidade. Daí indicar que todo conteúdo de ensino deve estar radicado na praticidade, no ensinar o que é imediatamente significativo, aplicável e útil.

Com efeito, percebe-se que está sendo criada uma nova mística acerca do professor. Visando retirar do mestre a identidade construída ao longo da história de seu ofício, o ardil consiste em esvaziá-la de seu sentido original e em seu lugar construir uma outra mentalidade: competitiva e individualista por excelência.

No Brasil, coerentemente com tal expropriação do saber docente, as tradicionais agências formadoras - e seus respectivos cursos Normal, no ensino médio, e de Pedagogia e Licenciaturas, no ensino superior - foram colocadas sob suspeita em termos de legitimidade formativa. A formação de docentes para séries iniciais do ensino fundamental e educação infantil, realizadas no Curso Normal, foi transferida para o nível superior, pela Lei de Diretrizes e Bases da Educação Nacional, de 1996. Entretanto, face ao contingente de professores a formar e à inexistência de agências formadoras em quantidade suficiente, a mesma Lei admite que essa formação ou seu equivalente - treinamento em serviço - mantenha-se em nível médio, no máximo, até dezembro de 2006. Espera-se que, a partir de então, a formação mínima exigida do docente seja exclusivamente a de nível superior, não necessariamente universitário. 
A solução encontrada, portanto, não foi a de manter e expandir a formação docente nos existentes cursos de Pedagogia e Licenciaturas nas universidades. $\mathrm{O}$ governo federal decretou a criação de Institutos Superiores de Educação (ISEs), vinculados ou não à universidade. Considerando a experiência de universitarização da formação docente, tais medidas podem ser consideradas um retrocesso. Desde o final dos anos de 1970 - anos do regime militar - setores críticos da área educacional construíram um projeto de formação que progressivamente se localizou no interior das universidades, sobretudo das públicas. Tratava-se de assegurar uma sólida formação, uma vez que o ambiente universitário poderia propiciar sua articulação com a pesquisa.

Evidentemente não se está afirmando que por se localizar na universidade o preparo do professor seja necessariamente adequado posto que também aí muitas das desejáveis condições de ensino e pesquisa não se realizam. Mesmo considerando este fator, ainda assim, o deslocamento da formação do professor para os Institutos Superiores de Educação poderá significar o rompimento de algumas das condições em que a relação ensino/pesquisa ocorre. $\mathrm{O}$ argumento fundamental do Estado, entretanto, não vê nesta quebra um prejuízo para a formação, dado que seu intento está marcado pelas demandas de constituição de um mercado pedagógico em um claro favorecimento à iniciativa privada no ensino superior.

A posição do governo federal esclareceu-se no Decreto $n^{\circ} 3.276$, de 06 de dezembro de 1999. O Decreto impôs que "a formação em nível superior de professores para a atuação multidisciplinar destinada ao magistério na Educação Infantil e nos anos iniciais do Ensino Fundamental, far-se-á exclusivamente em cursos normais superiores", sendo seu locus privilegiado os ISEs. Com isso, o Curso de Pedagogia perderá a prerrogativa de formar o docente. Esse curso, a continuar existindo, deverá dedicar-se ao preparo de especialistas, particularmente gestores educacionais, de que o projeto governamental não pode prescindir para asseverar o bom resultado de sua política.

O sentido da política desencadeada pelo governo federal brasileiro pode ser apreendido se relembrarmos os compromissos assumidos, em Jomtiem (1990), pelos representantes do país: expansão do atendimento à primeira infância, especialmente para as crianças pobres; acesso universal à educação básica até o ano $2000 ;{ }^{1}$ melhoria dos resultados da aprendizagem; redução da taxa de analfabetismo dos adultos; ampliação dos serviços de educação básica e de formação para outras competências necessárias a jovens e adultos. Passados dez anos, o Ministério da

\footnotetext{
${ }^{1}$ A educação básica corresponde em Portugal à escolaridade obrigatória de nove anos, isto é, ao ensino básico (dividido em três ciclos: $1^{\circ}$ ciclo -4 anos; $2^{\circ}$ ciclo -2 anos; $3^{\circ}$ ciclo -3 anos). $\mathrm{O}$ ensino secundário, com um único ciclo de 3 anos, é de freqüência facultativa. No caso do Brasil, a educação básica corresponde à Educação Infantil (0-6 anos), Educação Fundamental (7-14 anos) e Ensino Médio, sendo obrigatória somente a Educação Fundamental.
} 
Educação se obrigava a avaliar o andamento de sua política e apresentar a "lição de casa" às agências internacionais com as quais está comprometido, como atesta o Relatório EFA 2000.

Para justificar a criação dos ISEs, o governo brasileiro lançou mão de dados estatísticos que demonstram que, embora a taxa líquida de escolarização seja de $95,3 \%$ da população, há uma demanda da ordem de um milhão e duas centenas de milhar de docentes efetivamente qualificados para a educação básica. Perante índices aparentemente tão díspares pode-se indagar: por que isso ocorre?

Segundo o próprio Ministério da Educação, mais de 100 mil professores em exercício sequer completaram o $1^{\circ}$ grau, outros 100 mil possuem apenas o $1^{\circ}$ grau. A maior parte deste contingente - mais de 180 mil professores - está envolvida na delicada e complexa tarefa de alfabetizar. Nos termos definidos pela LDBEN seriam necessários, para suprir os déficits de funções docentes, a formação de 117 mil docentes para atuar de $1^{\mathrm{a}}$ a $4^{\mathrm{a}}$ séries, 51 mil para atuar de $5^{\mathrm{a}}$ a $8^{\mathrm{a}}$ e 215 mil para o Ensino Médio, incluindo os mais de 830 mil da Educação Infantil. Esses são os dados oficiais da Sinopse Estatística de 1996. Desse modo, argumenta o Estado, manter a formação do professor na universidade é posicionar-se contra a qualificação desse contingente de professores "leigos". Pode-se concluir, então, que a formação docente, no Brasil, está à deriva, pois os imperativos do sistema, ditados por critérios econômicos, a serem cumpridos em curto prazo (2006), sobrepõem-se a uma formação que responda qualitativamente à situação atual.

\section{Portugal: a universitarização da formação inicia}

Em Portugal, a institucionalização da formação inicial de docentes nas universidades ocorreu com a Reforma Veiga Simão, em 1973. Se a reforma foi inconseqüiente na sua efetivação para os ensinos médio e fundamental, devido à Revolução de 1974, o mesmo não se verificou para as políticas educacionais relativas à formação inicial, na medida em que a criação das denominadas "universidades novas" contribuiu não só para a gênese de um modelo inovador (com a integração das componentes curriculares), mas também para a questão da universitarização da formação dos professores. ${ }^{2}$ Com a criação das universidades novas, e perante as exigências sistêmicas da formação de um grande número de docentes, reclamados pela massificação escolar que se verificou a partir da década de 1970, a formação dos docentes apenas foi aligeirada no que diz respeito à duração do curso. Porém, a formação de três anos, em nível de bacharelado, passou para cinco anos em 1980, em nível de licenciatura. Esta formação abarcou somente

\footnotetext{
${ }^{2}$ Para além das universidades novas e das universidades clássicas, todas elas públicas, a formação inicial dos professores da educação infantil e dos professores para o ensino fundamental é realizada nas Escolas Superiores de Educação que também seguem o modelo integrado consagrado em 1973.
} 
os professores do ensino fundamental, a partir do $5^{\circ}$ ano, e os professores do ensino médio. A formação de cinco anos para os professores da educação infantil e do ensino fundamental, da $1^{\mathrm{a}}$ a $4^{\mathrm{a}}$ séries, foi decretada em 1998.

Nos anos 1980 e 1990, as políticas educacionais para a formação dos professores, em Portugal, correspondem não só à edificação de toda uma arquitetura jurídico-normativa, decorrente da Lei de Bases do Sistema Educativo, aprovada em 1986, mas também à redefinição do papel do professor como ator fundamental na transformação da sociedade. Reconhece-se que no quadro da sociedade do conhecimento a escola desempenha um papel primordial nas mudanças propostas. Por exemplo, o Relatório A escola e a qualidade, da Ocde, atribui ao docente uma centralidade em termos de ação com vista ao sucesso educativo dos alunos. Neste contexto, as principais alterações em Portugal estão consubstanciadas tanto no ordenamento jurídico da formação inicial (1989), como no da formação continuada (1990) de docentes. A leitura do preâmbulo destes dois documentos legais - os da formação inicial e continuada - indica que a formação de docentes é entendida como um fator que assegura a qualidade da escola.

No entanto, uma outra leitura pode ser realizada, quando se fala na formação dos professores como fator essencial para o bom desempenho dos alunos, a partir de importantes documentos publicados nos estados unidos e na Inglaterra que são suporte das políticas liberais contemporâneas. É sintomático que o relatório norte-americano, a nation at risk, de 1983, tenha recebido sua versão portuguesa, nos finais da década, no sentido de alertar a sociedade para os perigos de não se adotarem políticas educacionais que responsabilizassem as escolas e os professores pelo êxito dos alunos.

É neste sentido que é reconhecido em Portugal o fracasso da reforma educativa dos anos 80. Propõe-se, em contrapartida, uma reforma, revestida pelo conceito de "inovação", que se baseia, fundamentalmente, quer na flexibilização das políticas curriculares, quer na formação continuada obrigatória de docentes, constituindo um pré-requisito para a progressão na carreira, quer ainda na formação inicial, de nível de licenciatura, para os professores de educação infantil e dos ensinos médio e fundamental.

Implícito está que a formação inicial de docentes se faz predominantemente a partir de uma perspectiva profissionalizante, ou seja, o docente escolhe a sua profissão quando inicia o seu curso superior. Daí que ao longo dos cinco anos da formação, os planos curriculares façam a integração dos conteúdos disciplinares, dos conteúdos pedagógicos e da prática pedagógica que culmina com a realização de um estágio em uma escola real com alunos reais. 


\section{Perfil de competências}

Nas políticas educacionais sobre formação docente, tanto no Brasil como em Portugal, evidencia-se nos documentos legais uma dinâmica discursiva relativa à configuração das funções, dos papéis e das competências dos professores num perfil profissional. Uma interrogação pertinente, no entanto, pode ser colocada: qual a razão para que a noção de competência tenha adquirido centralidade na construção de um perfil profissional do docente? A resposta está em que ela faz parte de políticas educacionais que respondem a um duplo objetivo: de um lado, a descentralização e a responsabilização das escolas e dos docentes pelos resultados do sucesso dos alunos. A devolução de competências e a autonomia são faces de uma mesma moeda: transfere responsabilidades da esfera pública para a esfera privada (comunidades, pais, alunos, professores e outros); de outro, o reforço do papel centralizador do Estado na definição tanto dos parâmetros curriculares nacionais quanto dos seus conteúdos, métodos e avaliação.

A noção de competência impõe referenciais concretos cuja explicação não se encontra exclusivamente na escola, mas, ao contrário, na migração do campo da economia para o campo da educação. Não é sem razão que a discussão à volta da urgência da definição de um perfil de competências docentes esteja diretamente ligada ao Relatório A nation at risk. Trata-se de um documento que, embora referido ao domínio da educação, responde a imperativos macro-econômicos. A resignificação da educação não se faz agora pela pedagogia dos objetivos, como ocorreu na década de 1960, mas pela noção de competências, afirmando-se que a mediocridade da escola não resulta das políticas governamentais e das possibilidades de sua efetivação, mas da implementação dessas políticas pelas próprias escolas.

No caso do Brasil, por exemplo, a idéia de definir um perfil de competências surge, fundamentalmente, de discussões no Ministério do Trabalho e mais tarde articula-se aos parâmetros curriculares nacionais emanados do Ministério da Educação. Num contexto mais amplo, o perfil de competências associa as políticas educacionais às políticas econômicas, na medida em que, nos anos de 1980 a 1990, a teoria do capital humano é recuperada de modo a responder às novas demandas do mercado. De meados da década de 1990, em diante, a noção de competência começa a ser difundida nos documentos oficiais, mas é em maio de 2000, na Proposta de diretrizes para a formação inicial de professores da educação básica, em cursos de nível superior que essa noção é detalhadamente apresentada.

De acordo com a enunciada proposta, o termo competência se expressa de três modos - profissionalismo, ação teórico-prática e exercício profissional - que 
respondem a uma retórica que forja, no discurso oficial, uma legitimação para a expropriação do saber docente. Tal retórica acentua a tradicional tendência existente no Brasil de deslocamento para o normativo, prolixo e pormenorizado, da capacidade de resolver problemas que escapam à esfera de atuação dos professores. Em função desse deslocamento a proposta supracitada faz crer que o perfil de competências, por estar construído no espaço da regra, é um dispositivo que se auto-realiza. Desse modo, tal perfil valida os atributos dos que têm a responsabilidade de implementar, numa perspectiva técnica e apolítica, as decisões da administração.

A competência docente não é mais tecnicamente definida, como se verificou nos anos de 1960 e 1970, mas cognitivamente construída, sobretudo a partir dos trabalhos realizados no âmbito do "paradigma pensamento do professor" (WITTROCK, 1986). Porque o docente pensa e age, no contexto de diversos condicionalismos qualquer perfil de competências não pode ser um enunciado de regras que determinam comportamentos a partir de uma concepção meramente administrativa.

Quando falamos de uma construção cognitiva em termos de competências docentes não defendemos que o professor seja formado predominantemente na assunção de que a problematização e o questionamento da sua prática sejam suficientes. Trata-se de uma idéia generalizada que está presente no perfil de competências elaborado pelo Ministério da Educação brasileiro e que configura um nítido recuo da teoria no campo da formação dos professores. Mesmo que seja afirmado que a formação do docente deva ser realizada na relação teoria/prática, a concepção de teoria e prática presente na proposta é fortemente reducionista: prática compreendida como experiência presa ao empírico e ao imediato e teoria como sistematização e organização dessa experiência. É por isso que a formação de docentes pode ser feita em unidades de formação sem qualquer relação com as unidades de pesquisa. Portanto, a tendência brasileira parece encaminhar-se para uma certa fast teacher education em que a lógica de certificação é prevalecente em relação à lógica de formação.

A pesquisa em educação, nessa proposta, é tomada no sentido de "pesquisa didática" oposta à pesquisa científica e acadêmica (DIRETRIZES, 2000). Seu pragmatismo é efetivado no momento em que são selecionados aqueles conhecimentos que possam ser mobilizados na ação pedagógica. Dito de outro modo: é suficiente o conhecimento que tem alguma capacidade de responder e solucionar os problemas que a ação pedagógica exige. A prática reflexiva, o "saber fazer" docente, o saber prático, como paradigmas dominantes, enquadram-se pragmaticamente nos princípios advogados para a formação profissional. 
A formação centrada em competências é uma orientação política que funciona simultaneamente como um mecanismo de avaliação e como imposição de um currículo de formação quer nos conteúdos, quer nas instituições.

Em Portugal, no caso da formação inicial, esta avaliação funciona a priori mediante um processo de acreditação dos cursos. O surgimento, em 1998, do Instituto Nacional de Acreditação de Formação de Professores (Inafop) impõe a obrigatoriedade desse procedimento, funcionando como um mecanismo regulador dos preceitos legais instituídos. É nesse contexto que surge a definição de um perfil de competências.

$\mathrm{Na}$ legislação portuguesa reconhece-se que "o governo define, por Decreto-Lei, os perfis de competência e de formação de educadores e professores para o ingresso na carreira docente" (Lei ${ }^{\circ} 115 / 97$, de 19 de Setembro). O perfil de competências é entendido numa dupla perspectiva: formação comum a todas as qualificações profissionais para a docência; formação específica de cada qualificação de acordo com o grupo de docência e/ou ciclo e nível de ensino. Nesse momento, o Inafop tem em discussão um documento, que será o alicerce da definição do perfil de competências, intitulado Perfil geral de desempenho do educador e do professor. A questão que se coloca é esta: em que medida o perfil de desempenho do educador e do professor pode conciliar a tendência para a uniformização dos critérios de formação com a autonomia das instituições do ensino superior, responsáveis pela formação? Sobre esse aspecto, é interessante a leitura do Parecer do Conselho Nacional de Educação sobre a acreditação da formação inicial (CNE, 1999).

Uma questão é a definição de um quadro global de competências, que pode funcionar como instrumento de acreditação dos cursos, a outra é o processo de construção dos referentes mediante os quais se avalia o desempenho docente. O que se discute sobre o perfil de competências tem por base o trabalho de um Grupo de Missão que, em 1998 (PACHECO; FLORES, 1999), identificou as seguintes 10 dimensões do desempenho profissional do professor: perspectivar o sistema educativo na escola e na sala de aula; analisar problemas sociais contemporâneos; saber recolher e trabalhar a informação; conhecer conteúdos da área da docência; organizar processos de educação/ensino; adotar mecanismos de diferenciação pedagógica; estimular a participação no processo educativo; saber utilizar a avaliação; desenvolver o projeto educativo; saber atualizar-se e aperfeiçoar-se numa perspectiva pessoal, profissional e social.

\section{Palavras Finais}

O perfil de competências em vez de ser um mapa pormenorizado com os itinerários completos da formação, elaborado pelos Ministérios da Educação do 
Brasil e de Portugal, ou pelos seus órgãos descentralizados, deve ser um roteiro com percursos alternativos e diferençados que se coadunem quer com a autonomia e responsabilização das instituições do ensino superior, quer com os referentes que salvaguardem a coexistência de tipos distintos de paradigmas relativos à natureza do processo de ensino e aprendizagem.

Tais questões vêm se configurando como uma das temáticas fundamentais e prioritárias não só de órgãos governamentais, bem como de vários setores da sociedade - postos em ação pelo recuo progressivo do Estado particularmente no que respeita ao aspecto social. O docente, "vocacionado" para compreender e desenvolver a "sociedade educativa" e favorecer a coesão social, foi alçado ao papel de agente de mudança, como sugere o Relatório Jacques Delors, da Unesco (DELORS, 1998). Ademais, espera-se que o docente deva responsabilizar-se pela realização do ideário do século XXI, força discursiva determinante na articulação entre processo educativo e mundo produtivo: nacionalismo aliado a universalismo; preconceitos étnicos e culturais resolvidos com tolerância e pluralismo; totalitarismo suplantado pela democracia.

As políticas educacionais nos anos 90 reforçam, pois, a centralidade da formação dos profissionais da educação como um recurso de modernização da sociedade e dos sistemas de ensino. Se, por um lado, o docente tem sido desvalorizado em termos de status profissional, por outro, é também considerado um agente decisivo na construção do futuro, assumindo um protagonismo fundamental no ideário das reformas educacionais portuguesa e brasileira (LUDKE, MOREIRA e CUNHA, 2000). Daí que sua permanência nas políticas educacionais seja referenciada nos principais organismos nacionais, mundiais e multilaterais, como os Ministérios da Educação dos dois países, o Banco Mundial, Unesco, Cepal e UE.

Seria ilusão, por certo, presumir a questão da formação de professores como única preocupação nesse contexto. Ao contrário, uma verdadeira avalanche de resoluções, leis, pareceres e outros documentos nacionais e internacionais operam um verdadeiro "transformismo"3 na educação contemporânea. Um dos aspectos que merecem novos estudos é, justamente, o de procurar conhecer de que forma tais recomendações ingressam, se difundem, são acatadas, assimiladas, descartadas ou adaptadas pela onda legislativa que vem determinando os rumos das políticas educacionais, nos países envolvidos, nomeadamente no que diz respeito à formação de professores.

Ademais, tais recomendações harmonizam-se com o peculiar zelo de empresários na tentativa de formar o assim chamado "trabalhador de novo perfil", com maior competência técnica e atitudinal - e, sem dúvida, com o professor

\footnotetext{
${ }^{3}$ Recorremos ao conceito "transformismo", uma licença ao conceito gramsciano.
} 
amoldado à essa formação. Vale lembrar, apenas de passagem, que essa preocupação dos empregadores com a problemática educacional, durante muito tempo basicamente restrita à educação profissional, volta-se, a partir dos anos 90, para a escolaridade obrigatória (EVANGELISTA e SHIROMA, 1999).

Merece atenção o fato de que tal processo se faz acompanhar do caldeamento de um clima de consenso na sociedade. Importantes intelectuais contemporâneos que atuam em departamentos de educação de organismos multilaterais, assim como em instituições educacionais, vêm publicando artigos de ampla circulação nacional e internacional alardeando tais reformas e recomendações como as melhores - senão as únicas - alternativas para a resolução dos problemas da educação (TEDESCO, 1998; TORRES, 1995, 1999; MOURA CASTRO, 1994, 1997; CASASSUS, 1993, 1998, entre outros). São inúmeros os documentos, nos dois países, que utilizam estratégias sofisticadas de linguagem para apresentar novos conceitos e ressignificar outros.

Assim, o complemento teórico necessário das políticas em foco encontrase no campo da teoria, na forja pragmática de um novo vocabulário - processo também denominado criação de "novos desenhos conceituais" - que impõe uma ressignificação de conceitos, categorias, termos e sinais, de modo a torná-los condizentes com os emergentes paradigmas que referenciam a transformação almejada para a educação contemporânea. Competência, equidade, eficácia, eficiência, gestão, destreza, consenso, sociedade civil, democracia, cidadania, tolerância, edificação, professor, solidariedade, racionalidade, verdade, conhecimento, entre outros, são todos tragados pela retórica neopragmática em vigor e adquirem sentido e significado adequados aos novos tempos (MORAES, 2000).

Esse é o universo de questões que, a nosso ver, afronta, hoje em dia, os educadores. É nele que se efetivam as nossas inquietações sobre os valores e os fins, sobre a nossa prática e sobre as perspectivas teóricas que adotamos.

\section{RFERÊNCIAS}

BRASIL. Ministério da Educação (1996). Lei n. 9394 de 20 de dezembro de 1996. Lei e Diretrizes e Bases para Educação. Diário Oficial da República Federativa do Brasil, Brasília, dez. 1996.

BRASIL. Ministério da Educação. Projeto de estruturação do Curso Normal Superior. Brasília, maio 2000 . 
PACHECO, J. A. Et al. Políticas educacionais nos anos 90: a formação...

BRASIL. Ministério da Educação. Proposta de diretrizes para a formação inicial de professores da educação básica em cursos de nível superior. Brasília, maio 2000.

BRASIL. Ministério da Educação. A Declaração de Nova Delhi. Brasília, 1993.

BRASIL. Ministério da Educação; Conselho Nacional de Educação. Diretrizes gerais para a formação do professor, nos termos dos artigos 63 e 64 da Lei 9394/96, Brasília, fev.1998.

BRASIL. Ministério da Educação, Secretaria de Educação Fundamental. Referencial Pedagógico Curricular para a Formação de Professores da Educação Infantil e Série Inicial do Ensino Fundamental, Brasília, dez.1997.

BRASIL. Ministério da Educação. Relatório EFA 2000. Brasília: MEC,2000.

BRASIL. Ministério da Educação. Proposta de Diretrizes para a Formação Inicial de Professores da Educação Básica, em Cursos de Nível Superior, Brasília: MEC,2000.

CASASSUS, J. Debe el Estado ocuparse aún de la educación? Análisis desde las dimensiones de la regulación y de la legitimación, Unesco/Orealc. Boletin Proyecto Principal de Educación en América Latina y Caribe, n. 30, abril, 1993.

CASSASSUS, J. Tarefas da Educação. Campinas: Autores Associados, 1998.

CASTRO, C. M. Educação brasileira: concertos e remendos. Rio de Janeiro: Rocco, 1994.

CASTRO, C. M.; CARNOY, M. (org.) Como anda a reforma da educação na América Latina? Rio de Janeiro: FGV, 1997.

DELORS, J. Educação - um tesouro a descobrir. Relatório para a Unesco da Comissão Internacional sobre Educação para o século XXI. São Paulo: Cortez. 1998. 
PACHECO, J. A. Et al. Políticas educacionais nos anos 90: a formação...

EVANGELISTA, O.; MORAES, M. C. M. Universidade brasileira: de alma mater a causa mortis. In: III CONGRESSO LUSO-BRASILEIRO DE HISTÓRIA DA EDUCAÇÃO, 3. 2000, Coimbra. Anais... Coimbra: Universidade de Coimbra, fev. 2000 (Texto impresso)

EVANGELISTA, O.; SHIROMA, E. O. As políticas internacionais para a educação e suas repercussões no Brasil, Florianópolis: UFSC/ PPGE, 1999. Texto para Discussão.

EVANGELISTA, O.; SHIROMA, E. O. Ode à diversidade: do Tour d'argent ao bandejão. Florianópolis: UFSC/PPGE, 2000. Texto para Discussão.

EVANGELISTA, O., MORAES, M. C. M.; SHIROMA, E. O. Políticas educacionais: história e crítica. Rio de Janeiro: DP\&A, 2000. (O que você precisa saber sobre).

EVANGELISTA, O., SHIROMA, E.; MORAES, M. C. M. Educação continuada e contrução de competências: formação de educadores e educadoras em um mundo em mudança, Florianópolis: UFSC/PPGE, 1999. Texto para Discussão.

LASH, S. Crítica da informação. Revista Crítica de Ciências Sociais, n. 54. 1999.

LUDKE, M.; MOREIRA, A. F.; CUNHA, M. I. Repercussões de tendências internacionais sobre a formação de nossos professores. Educação e sociedade, n. 68, 2000. 2. ed.

MORAES, M. C. M. Paradigmas emergentes: novos desenhos conceituais na formação de educadores, projeto de pesquisa, CNPq. [S. 1.: s. n.. 2000]. Texto impresso.

MORAES, M. C. M. O recuo da teoria: impactos na pesquisa em educação. Revista Portuguesa de Educação, Instituto de Educação e Psicologia, Universidade do Minho, 2000. No prelo.

OCDE. A escola e a qualidade. Porto: ASA, 1992.

PACHECO, J.; FLORES, M. A. Formação e avaliação de professores. Porto: Porto Editora, 1999. 
PACHECO, J. A. Et al. Políticas educacionais nos anos 90: a formação...

PORTUGAL. Parecer do Conselho Nacional sobre Acreditação da Formação Inicial. Lisboa: Conselho Nacional de Educação/Ministério da Educação, 1999. <http://www.cnedu$\mathrm{pt}>$.

PORTUGAL. Ministério da Educação. Lei n. 46 de 1986. Lei de Bases do Sistema Educativo, alterada pela Lei n. 115/97 no que diz respeito à Formação Inicia. Lisboa, 1986.

PORTUGAL. Ministério da Educação. Decreto Lei n. 344 de 1989. Ordenamento Jurídico da Formação de Educadores de Infância e de Professores dos Ensinos Básico e Secundário. Lisboa, 1989.

PORTUGAL. Ministério da Educação. Decreto Lei n. 242 de 1992. Regime Jurídico da Formação Contínua dos Professores de Educação Pré-escolar e dos Ensinos Básico e Secundário. Lisboa, 1992.

PORTUGAL. Ministério da Educação. Decreto Lei n. 290 de 1998. Lei orgânica do Instituto Nacional de Acreditação de Formação de Professores. Lisboa, 1998.

TEDESCO, J. C. O Novo Pacto Educativo. São Paulo: Ática, 1998.

TORRES, R. M. Que (e como) é necessário aprender? Necessidades básicas de aprendizagem e conteúdos curriculares. 2. ed. Campinas: Papirus, 1998.

TORRES, R. M. Una década de "educación para todos": lecciones para el futuro. Buenos Aires: [s. n.], 1999. Texto impresso.

TOURAINE, A. Como sair do liberalismo? Lisboa: Terramar, 1999.

WITTROCK, M. (Ed.). Handbook Research on Teaching. 3. ed. New York: MacMillan, 1986. 